\title{
Bridging the Molecular-Cellular Gap in Understanding lon Channel Clustering
}

\author{
Valerie Abigail Nirenberg and Ofer Yifrach * \\ Department of Life Sciences and the Zlotowski Center for Neurosciences, Ben-Gurion University of the Negev, Be'er Sheva, Israel
}

OPEN ACCESS

Edited by:

Moran Rubinstein,

Tel Aviv University, Israel

Reviewed by:

Daniel Yakubovich,

Tel Aviv University,

Israel

Carlos Alberto Villalba-Galea, University of the Pacific,

United States

*Correspondence:

Ofer Yifrach

ofery@bgu.ac.il

Specialty section:

This article was submitted to Pharmacology of Ion Channels and Channelopathies, a section of the journal

Frontiers in Pharmacology

Received: 24 September 2019 Accepted: 16 December 2019

Published: 29 January 2020

Citation:

Nirenberg VA and Yifrach O (2020) Bridging the Molecular-Cellular Gap in Understanding lon Channel Clustering. Front. Pharmacol. 10:1644. doi: 10.3389/fphar.2019.01644
The clustering of many voltage-dependent ion channel molecules at unique neuronal membrane sites such as axon initial segments, nodes of Ranvier, or the post-synaptic density, is an active process mediated by the interaction of ion channels with scaffold proteins and is of immense importance for electrical signaling. Growing evidence indicates that the density of ion channels at such membrane sites may affect action potential conduction properties and synaptic transmission. However, despite the emerging importance of ion channel density for electrical signaling, how ion channel-scaffold protein molecular interactions lead to cellular ion channel clustering, and how this process is regulated are largely unknown. In this review, we emphasize that voltagedependent ion channel density at native clustering sites not only affects the density of ionic current fluxes but may also affect the conduction properties of the channel and/or the physical properties of the membrane at such locations, all changes that are expected to affect action potential conduction properties. Using the concrete example of the prototypical Shaker voltage-activated potassium channel (Kv) protein, we demonstrate how insight into the regulation of cellular ion channel clustering can be obtained when the molecular mechanism of ion channel-scaffold protein interaction is known. Our review emphasizes that such mechanistic knowledge is essential, and when combined with super-resolution imaging microscopy, can serve to bridge the molecular-cellular gap in understanding the regulation of ion channel clustering. Pressing questions, challenges and future directions in addressing ion channel clustering and its regulation are discussed.

\section{Keywords: action potential, clustering, coupling, ion channel density, potassium channels, sodium channels} post-synaptic density-95, scaffold proteins

\section{INTRODUCTION}

The precise localization, distribution, and density of voltage-activated ion channels at specific neuronal membrane sites are essential for action potential (AP) generation and propagation and for synaptic transmission (Hille, 1992). Ion channels are not randomly distributed in the membrane, as would be assumed by the Singer-Nicolson fluid mosaic membrane model (Singer and Nicolson, 1972), but instead are targeted to specific sites, such as axon initial segments (AIS), nodes of Ranvier (NR) or the post-synaptic density (PSD), where they are usually part of highly regulated multiprotein macromolecular complexes (Lai and Jan, 2006). Transcriptional activators and suppressors, 
cytoskeletal proteins, cell adhesion molecules, post-translational signaling molecules, ion channel auxiliary subunits, and scaffold proteins are co-targeted with ion channels to such sites. The final endpoint in assembling such complexes is not only the proximity of the ion channel and its auxiliary subunits and/or modulatory proteins but also the clustering of many ion channel molecules together, potentially, within interaction distances (Engelman, 2005; Han and Kim, 2008; Freeman et al., 2016; Capera et al., 2019). The density of ion channel molecules at these sites, i.e., the number of molecules per membrane area, is thus an important parameter, and the question then arises what are the potential functional consequences of having many neighboring ion channel molecules aggregated together in one site with respect to electrical signaling? Furthermore, how the density of ion channel proteins at their specific membrane targeting sites are spatially and temporally regulated, to affect AP conduction properties, is largely unknown.

In the current review, we highlight the importance of ion channel clustering and its regulation for electrical signaling. We begin by concisely surveying where and how different voltageactivated ion channels are targeted to primary sites along the polarized neuron in the direction of AP propagation. We then present cases where ion channel density was shown to affect not only the density of ionic current fluxes at their site of expression but also the gating properties of ion channels, relative to their function in an isolated context, and the physical properties of the membrane. We discuss the functional consequences of such changes on AP conduction properties and further emphasize the important role played by scaffold proteins in mediating voltage-dependent ion channel clustering. Finally, by using the concrete example of the voltage-activated potassium channel protein, we highlight that when the molecular mechanism underlying the ion channel-scaffold protein interaction is known, cellular understanding regarding the regulation of ion channel density can be obtained. This example demonstrates the strength of adopting a mechanistic view in bridging the molecular-cellular gap in the understanding of ion channel clustering. We end with a summary of current challenges and consider future directions that can be taken for better understanding ion channel clustering.

\section{SITE-SPECIFIC CLUSTERING OF ION CHANNELS AFFECTS SIGNAL GENERATION, PROPAGATION, AND TRANSMISSION}

Action potentials are transient changes in membrane polarization that spread in space and time along neurons or muscle cells, for example. Such perturbations result from choreographed changes in membrane conductance, primarily by $\mathrm{Na}^{+}$and $\mathrm{K}^{+}$ions, brought about by opening, closing, and inactivation gating transitions of voltage-activated sodium $(\mathrm{NaV})$ and potassium $(\mathrm{Kv})$ ion channels, respectively. One can encounter clusters of the various voltage-dependent ion channels starting at the neuronal soma, continuing along the axon and across the synapse (Figure 1). AP generation relies on proper enrichment of $\mathrm{Na}^{+}$and $\mathrm{K}^{+}$voltage-gated ion channels to the AIS, where the axon begins to extend from the soma

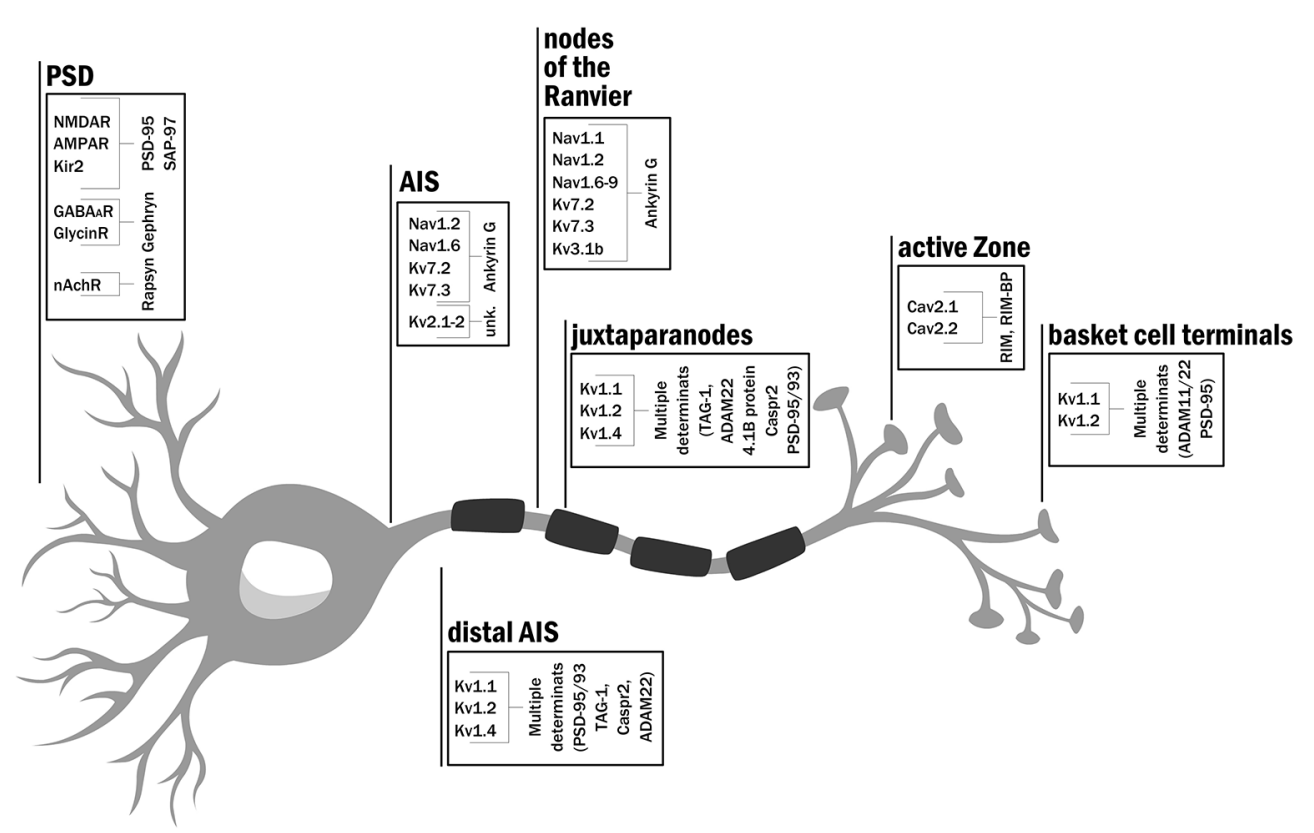

FIGURE 1 | Clustering geography: the distribution of ion channels and scaffold proteins along the neuron. Schematic representation of a typical neuron specifying the type of ion channel and scaffold proteins targeted and clustered to the axon initial segment, node of Ranvier, active zone and at the postsynaptic densities (in dendrites). A full reference list supporting the indicated location for each channel subtype is given in SI Text $\mathbf{1}$. 
(Hille, 1992; Kole et al., 2007; Kole et al., 2008; Jensen et al., 2017). Membrane depolarization occurs with high efficiency at the AIS, with voltage-activated sodium channel subtypes 1.2 and 1.6 (NaV1.2 and NaV1.6) corresponding to the dominant ion channel types clustered at this region (Tian et al., 2014) (Figure 1). Disruption of $\mathrm{NaV}$ channel cluster formation at the AIS in mouse cerebellum Purkinje cells led to delayed AP initiation and a reduced maximal firing rate (Zhou et al., 1998). These effects emphasize the importance of $\mathrm{NaV}$ channel clusters at the AIS for normal electrical signaling. Kv channels were also shown to be part of the high-density channel repertoire at the AIS (Figure 1). While Kv2.1 channel clusters are seen at specific subdomain patches of the AIS (Trimmer, 1991; Scannevin et al., 1996; Sarmiere et al., 2008), Kv7, and Kv1 channel subtypes (KCNQ and Shaker-type channels), respectively, reside at the proximal (Klinger et al., 2011) and distal regions of the AIS (Kole et al., 2007), adjusting the threshold, inter-spike interval, and firing frequency characteristics of the action potential.

As the AP propagates down the myelinated axon, high densities of $\mathrm{NaV}$ and $\mathrm{Kv}$ channels are encountered at nodes of the Ranvier (Figure 1). Here, targeting and clustering of these channels are essential for AP saltatory conduction along the axon (Rasband and Trimmer, 2001). The nodal membrane was reported to express clusters of multiple $\mathrm{NaV}$ channel subtypes, including NaV1.1, NaV1.2, NaV1.6, NaV1.7, Nav1.8, and NaV1.9 channels (Chang and Rasband, 2013). Kv channel subtypes 1,3 , and 7 were also reported to reside and cluster at nodal sites. Whereas Kv7.2, Kv7.3, and Kv3.1 channels were shown to be responsible for the repolarization of the axonodal membrane (Devaux et al., 2003; Devaux et al., 2004; Klinger et al., 2011; Trimmer, 2015), the Kv1 channel subfamily (Kv1.1, $\mathrm{Kv1.2}$, and $\mathrm{Kv1.4}$ ) is clustered at juxtaparanodal regions (Poliak et al., 2003; Rasband, 2004) and serves to adjust AP propagation along the myelinated axon. Pharmacologically blocking these channels resulted in prolonged action potentials (Devaux et al., 2002).

Progressing along the axon towards its terminal, one reaches the active zone (AZ), the next site where ion channels are clustered (Figure 1). In this region, proteins of the vesicle release machinery involved in synaptic transmission are tightly docked (Südhof, 2012). In particular, voltage-activated $\mathrm{Ca}^{2+}$ channels ( $\mathrm{N}$ and $\mathrm{P} / \mathrm{Q}$ types, specifically CaV2.1 and 2.2, respectively) are clustered at this site to ensure the economic and directed release of neurotransmitters into the synaptic cleft (Kaeser et al., 2011; Gundelfinger and Fejtova, 2012). Following the release, neurotransmitters diffuse across the synaptic cleft and bind to excitatory or inhibitory ligand-gated ionotropic receptors that are aggregated at the post-synaptic density membrane (PSD). The PSD has mostly been studied in glutamatergic neurons, where AMPA and NMDA ionotropic receptors are clustered, proximal to the pre-synaptic AZ sites (Boeckers, 2006; Chen et al., 2015; Tang et al., 2016; Scheefhals and MacGillavry, 2018). Ionotropic glycine receptor clustering was also reported in the membrane of the postsynaptic cell (Patrizio et al., 2017; Schaefer et al., 2018). Such clusters are found in motor neuronal membranes of the adult spinal cord, brain stem, and retina, and were shown to be essential for proper neuron hyperpolarization. Impaired clustering of glycine receptors is associated with startle disease in mice (Patrizio et al., 2017; Schaefer et al., 2018). The clustering of different ion channels and receptors in proximity to other intracellular signaling and cytoskeletal structural proteins at the PSD is also essential for ensuring a robust response to neurotransmitter binding and for modulating the evoked synaptic potential, whether inhibitory or excitatory, of the post-synaptic cell membrane (Boeckers, 2006). A robust response to neurotransmitter release also occurs at the neuromuscular junction (NMJ) where it is essential for muscle contraction. Thousands of copies of nicotinic acetylcholine receptors (nAchRs) are clustered at the post-synaptic muscle cell (Peng and Poo, 1986; Bruneau et al., 2008). The opening of these nonselective ligand-gated cation channels in response to acetylcholine release allows the diffusion of primarily $\mathrm{Na}^{+}$ions across the muscle cell membrane to achieve efficient muscle cell membrane depolarization and subsequently contraction (Bruneau et al., 2008; Slater, 2017; Burden et al., 2018). A detailed reference list summarizing available information attesting to the targeting of a specific ion channel subtype to the indicated neuronal membrane sites is given in SI Text 1.

\section{THE HIDDEN DIMENSION OF ION CHANNEL CLUSTERING: THE DIFFERENT MODES BY WHICH ION CHANNEL DENSITY MAY AFFECT AP CONDUCTION PROPERTIES}

The density of aggregated voltage-dependent ion channel molecules at their unique sites of targeting may affect AP conduction properties via three distinct, non-mutually-exclusive modes. First and straightforward, voltage-dependent ion channel density at the sites of channel expression directly dictates the density of inward or outward $\mathrm{Na}^{+}$or $\mathrm{K}^{+}$ionic currents, upon changes in membrane polarization. Second, ion channel density by itself may affect activation and/or inactivation gating transitions of the channel, as compared to the isolated channel scenario. Last, the accumulation of densely-packed voltageactivated ion channel molecules, with their multiple positively charged voltage-sensing domains, might affect the capacitance property of the membrane at such sites, potentially affecting the cable properties of the axon. As we concisely summarize below, all three functional consequences of changes in ion channel density are expected to affect AP conduction properties.

Several years before the seminal papers of Hodgkin and Huxley, describing the theory behind action potential generation (Hodgkin and Huxley, 1952; Huxley, 1964), Hodgkin described a set of experiments on Carcinus maenas crab axons demonstrating two, low- and high-frequency, repetitive firing modes (Hodgkin, 1948). These experiments provided a solid base for the current understanding of AP firing modes exhibited by pyramidal neurons (Tateno and Robinson, 2006) and interneurons (Tateno and 
Robinson, 2007). The two neuronal excitability modes were used to rationalize coding properties of neurons (Rinzel and Ermentrout, 1998; St-Hilaire and Longtin, 2004; Tateno et al., 2004; Tateno and Robinson, 2006; Tateno and Robinson, 2007). It has long been thought that different combinations of ion channel types may explain the observed differences in firing patterns (Prescott et al., 2008). In recent years, however, theoretical and experimental evidence has been accumulated to show that changes in the densities of voltage-gated $\mathrm{Na}^{+}$and $\mathrm{K}^{+}$channels alone can explain the dynamic switch of a neuron between the low and highfrequency firing modes (Århem et al., 2006; Århem and Blomberg, 2007; Zeberg et al., 2010; Zeberg et al., 2015). Such changes in ionic current densities are reflected by changes in the membrane permeability to $\mathrm{Na}^{+}$and $\mathrm{K}^{+}$ions when all channels are open. In the native channel context, such modulation of ion channel densities may be brought about by specific channel blockers that serve to reduce the nominal number of active channels per site (Zeberg et al., 2010). These later studies directly demonstrate how changes in ionic current densities may affect AP conduction properties and information coding.

Changes in ion channel densities at their native clustering sites may further affect the gating properties of the ion channel. Ion channel gating is often studied in an isolated channel context, with the ion channel being expressed in the membrane of a heterologous expression system (Furutani and Kurachi, 2012). Activation and slow or fast channel inactivation of voltage-dependent channels are then studied using electrophysiological recording techniques, with the singlechannel recording being one of the most direct and thorough methods for studying ion channel gating and regulation (Sakmann and Neher, 1984). Clearly, the targeting of ion channels to native sites along with their adjacent modulatory subunits and regulatory proteins affects the gating properties of the channels (O'Connell et al., 2010; Zhang et al., 2016; Vivas et al., 2017). What we wish to emphasize here is that the density of ion channels at native clustering sites by itself may affect the channel activation and inactivation gating properties, thus affecting AP conduction properties. This dimension is frequently overlooked when addressing channel clustering. Several examples of such density-mediated modulation of channel gating have been reported. First, the density of the prototypical bacterial $\mathrm{KcsA} \mathrm{K}^{+}$channel expressed in liposomes was shown to affect the open probability of the channel (Molina et al., 2006; Sumino et al., 2014). The mechanism underlying such effects on channel activation gating is, however, not yet clear. Another example is the L-type CaV1.2 channel expressed in native cardio-myocyte cells. CaV1.2 channels were shown reside within small clusters (5-10 molecules) and appear to open synchronously in response to membrane depolarization (Dixon et al., 2015). Furthermore, prolonged open channel duration was observed for the clustered channels, as compared to the isolated channel case, suggesting that activation gating is affected (Dixon et al., 2015; Folci et al., 2018). The functional coupling between multiple ion channels can also be inhibitory. For instance, Kv2.1 channels were reported to exhibit a non-conductive phenotype when clustered at high densities (Scannevin et al., 1996;
O'Connell et al., 2010; Fox et al., 2013; Liu et al., 2016). Clearly, in all these examples, although no mechanisms were suggested, it is reasonable to assume that short-range intermolecular allosteric interactions are responsible for the observed coupling effects. Such changes in ion channel gating properties due to changes in channel density would affect the kinetics of ionic current development with time (i.e. the rate constants for activation and inactivation channel processes) and are expected to affect AP shape and conduction properties (Debanne et al., 1997; Giese et al., 1998; Johnston et al., 1999).

Another dimension of voltage-dependent ion channel density concerns their potential effect(s) on the physical properties of the membrane at the clustering site. Such effects may be brought about by the proximity of many charged voltage sensor domains resulting in changes in membrane thickness and/or its effective dielectric constant, both properties that affect membrane capacitance. The first report concerning potential effects of channel overexpression on membrane properties concerned the channelrhodopsin-2 light-gated ion channel (Zimmermann et al., 2008). Overexpression of the protein in HEK293 cells resulted in changes in the morphology of the cell mabrane reflected in an increase in membrane capacitance. This effect was not observed upon physiological expression levels of the channel (Zimmermann et al., 2008). Furthermore, recordings from tsA201 and PC12 cells overexpressing the Ciona intestinalis voltage-sensing phosphatase protein (CiVSP) revealed an increase of the local membrane capacitance upon voltage activation of the protein (Hossain et al., 2008; Lundby et al., 2008). The additional capacitance component termed "sensing capacitance" was further investigated by computational simulations of neuronal model cells expressing the voltage-sensing fluorescent proteins VSFP2.3 and VSFP3.1 (Akemann et al., 2009). The results revealed that changes in expression levels of these proteins resulted in changes in membrane capacitance due to changes membrane topology and/or mobility of channel gating, leading to changes in the effective diaelectric constant of the membrane. The simulations revealed that such changes lead to an increase of the threshold for AP spike initiation (Akemann et al., 2009). Although these studies relate to changes in the expression levels of these voltage-sensing domain-containing proteins as causing changes in membrane capacitance, such changes, are of course, related to changes in the density of these proteins per membrane area. The end result is that for voltage-sensor containing proteins, regulation of protein clustering affects membrane capacitance properties and hence, cable properties of the axon. It remains to be shown whether such "sensing capacitance" effects are also observed for native voltagedependent sodium and potassium ion channel proteins.

Taken together, the results summarized here emphasize that understanding of how ion channel density within clustering sites is regulated is of paramount importance in considering electrical signaling, with changes in ion channel density exerted through changes in membrane ionic current densities, in channel gating properties and/or membrane capacitance, dramatically affecting AP shape, frequency and information coding in neurons. 


\section{MOLECULAR AND CELLULAR GAPS IN UNDERSTANDING ION CHANNEL CLUSTERING}

The family of scaffold proteins is central for targeting and clustering of ion channels at native membrane sites (Good et al., 2011). Such clustering can be revealed by confocal light microscopy imaging of heterologous cells transfected to express both the ion channel and scaffold proteins and is manifested as a speckled colocalization pattern of fluorescently-tagged versions of both proteins in the cell membrane (Tejedor et al., 1997). Scaffold proteins correspond to many different and structurally unrelated protein subfamilies that seem to share similar functional roles. They are multi-domain proteins that interact with ion channels and membrane receptors (as well as with other membrane-embedded proteins) on the one hand, and with other intracellular signaling and skeletal proteins on the other. Scaffold proteins thus link membrane-associated events with downstream signaling pathways (Good et al., 2011; Zheng et al., 2011; Lee et al., 2014).

Here, we consider several examples of scaffold proteins encountered along the length of the neuron (Figure 1). Ankyrin G scaffold proteins interact with $\mathrm{NaV}$ channel isoforms at nodal and AIS sites and further bind to the intracellular BIV-spectrin protein (Zhou et al., 1998; Komada and Soriano, 2002). This latter protein further interacts with actin, a major component of the cytoskeletal network. The interaction between ankyrin $\mathrm{G}$ and $\mathrm{NaV}$ channels in the rat is mediated by a nine amino acid motif within the second intracellular loop of the $\mathrm{NaV} 1.2$ channel and leads to $\mathrm{NaV}$ channel clustering (Lemaillet et al., 2003). How ankyrin $\mathrm{G}$ serves to dock and cluster $\mathrm{NaV}$ channel molecules is not yet known. The clustering of calcium channels at the pre-synaptic AZ offers another example. Here, the scaffold protein of focus is the RIM (Rab3-interacting molecule) protein (Südhof, 2012). RIM proteins were proposed to interact via their PDZ protein-protein interaction modules with a cytoplasmic C-terminal PDZ-binding motif presented by $\mathrm{N}$ and $\mathrm{P} / \mathrm{Q}$ type voltage-activated $\mathrm{Ca}^{2+}$ channels (Kaeser et al., 2011). Such interaction allows for tethering these channels at the $\mathrm{AZ}$ in high copy numbers. For example, around $100 \mathrm{CaV} 1.3$ and $\sim 10 \mathrm{CaV} 2.1$ channel molecules reside in AZ clusters of hippocampal Purkinje neurons, with several such clusters being noted per AZ (Miki et al., 2017). RIM proteins also interact with several other vesicle-release proteins in the $\mathrm{AZ}$ complex (Krinner et al., 2017). The RIM scaffold protein thus mediates coupling between the $\mathrm{CaV}$ channel and vesicle docking machinery proteins and is essential for synchronous neurotransmitter release at the AZ. Still, it remains to be determined whether or not $\mathrm{CaV}$ channel-RIM protein-protein interactions affect $\mathrm{Cav}$ gating. The last example concerns the scaffold protein-mediated clustering of different ion channels and receptors at the PSD (Gomperts, 1996). Here, the dominating scaffold protein family is the membrane-associated guanylate kinase (MAGUK) family, the most intensively studied of all scaffold proteins. Relying on their multiple domains, MAGUKs serve as linker proteins that couple membrane events with downstream intracellular signaling (Zheng et al.,
2011; Chen et al., 2015). Similar to RIMs, MAGUK proteins also carry PDZ domains capable of binding the C-terminal motifs of several membrane-embedded ion channels, receptors, and cell adhesion proteins (Li et al., 2000; Lee and Zheng, 2010). Other modular domains of MAGUKs, such as its $\mathrm{SH} 3$ and guanylate kinase-like domains, serve as hubs for signaling control and interact with other PSD components, such as the adhesion protein ADAM22, A-kinase anchor proteins (AKAPs), actin dynamic modulators (such as SPIN90/WISH) (Lee et al., 2006; Han and Kim, 2008; Verpelli et al., 2012; Frank and Grant, 2017) and other scaffolding proteins [such as guanylate kinaseassociated protein (GKAP) family members]. PSD-95 and SAP97, two members of the MAGUK family of scaffold proteins, were shown to be responsible for AMPAR, NMDAR and Kir2 channel clustering at the PSD site of glutamatergic synapses (Cohen et al., 1996; Gomperts, 1996; Chen et al., 2015; Hoffmann et al., 2015). PSD-95 and SAP-97 were also shown to interact with members of the Kv1 (Shaker-type) subfamily (Gomperts, 1996; Tiffany et al., 2000). PSD-95 and PSD-93 were also reported to be essential for the proper clustering of Shaker channels at the AIS (Ogawa et al., 2008), at membranes of basket cell terminals (Rasband, 2010) and in smooth muscle cells (Joseph et al., 2011) but not in the juxtaparanodes (Rasband et al., 2002). Although Kv1 channels and PSD-95 co-localize at the juxtaparanode (Rasband, 2004; Arancibia-Carcamo and Attwell, 2014), clustering does not seem to depend on PSD-95 and as such, its role in the juxtaparanodal scaffold is still questioned. A detailed reference list supporting the findings indicated above is provided in SI Text 1.

The examples above, and others not addressed here demonstrate that ion channel clustering at distinct neuronal membrane sites primarily involves the direct binding of the channel to its cognate scaffold protein partner. In some cases, the ion channel and the scaffold protein binding partners are known. However, how this molecular binding event leads to cellular ion channel clustering involving many molecules is utterly unknown for almost all ion channel proteins. Furthermore, we generally do not know if and how ion channel membrane density is regulated in the spatial and/or temporal dimensions. These questions reflect what we refer to as a molecular-cellular gap that hampers our understanding of ion channel clustering. Indeed, many questions concerning the scaffold protein-ion channel interacting pair have yet to be answered. What is the stoichiometry of the interaction? How is ion channel density regulated in both the spatial and temporal dimensions? How is cluster area size determined? How do other proteins serve to regulate the clustering process? How many ion channel molecules usually reside in such clusters? Are there direct inter-molecular channel-channel interactions within clusters? To begin answering these questions, insight into the molecular mechanism underlying the binding of a channel to its cognate scaffold protein must be obtained. As will be demonstrated in the following section using the concrete example of the Shaker Kv channel-PSD-95 interaction, where such mechanistic knowledge is available, valuable insight into the mechanism of ion channel clustering is at hand. 


\section{BRIDGING THE MOLECULAR-CELLULAR GAP IN UNDERSTANDING KV CHANNEL CLUSTERING}

Members of the Shaker Kv channel family were previously discovered to cluster upon channel interaction with the PSD95 scaffold protein (Kim et al., 1995; Tejedor et al., 1997). This interaction is mediated by PDZ-binding motifs located at the extended C-terminal region of the channel that binds to the PSD95 PDZ domains. Mutations in the PDZ-binding motif of the prototypical Drosophila melanogaster Shaker Kv channel were found to impair both PSD-95 association and clustering. Eliminating this motif resulted in a diffusive channel expression pattern in the membrane of heterologous cells transfected to express the mutant channel and PSD-95 (Kim et al., 1995; Tejedor et al., 1997; Tiffany et al., 2000). In recent years, our lab has revealed the molecular mechanism underlying the Shaker Kv channel-PSD-95 interaction (Magidovich et al., 2007; Zandany et al., 2015a). This mechanism is referred to as a 'ball and chain' binding mechanism and is depicted in Figure 2 (upper panel). According to this mechanism, and in analogy to the fast inactivation gating of $\mathrm{NaV}$ and $\mathrm{Kv}$ channels (Armstrong and Bezanilla, 1977; Armstrong, 1981; Hoshi et al., 1990), the channel's cytoplasmic C-terminal tail contains an extended intrinsically disordered amino acid "chain" (Magidovich et al., 2007), bearing a conserved PDZ-binding motif (the "ball") at its tip (Magidovich et al., 2007; Zandany et al., 2015a). The random walk motion of the "chain" serves to search and recruit the PSD95 scaffold protein partner (Figure 2 upper panel), in a manner analogous to the role of the extended $\mathrm{N}$-terminal $\mathrm{Kv}$ channel tail in regulating fast channel inactivation (Hoshi et al., 1990). In this inactivation process, the stretch comprising the terminal 20 amino acids of the channel, corresponding to the inactivation "ball", is guided by a random walk search of the attached "chain" for its receptor site in the inner cavity of the open ion conduction pore domain, thus blocking the flow of $\mathrm{K}^{+}$current through the channel. In both "ball and chain" mechanisms, either the N-or C-terminal "chains" belong to the class of entropic chains of intrinsically-disordered proteins (Dunker et al., 2001; Dunker et al., 2002; Uversky and Dunker, 2010) and function as entropic clocks (Dunker et al., 2001) to time channel entry into inactivation or PSD-95 binding, respectively (Hoshi et al., 1990; Zandany et al., 2015a; Zandany et al., 2015b).
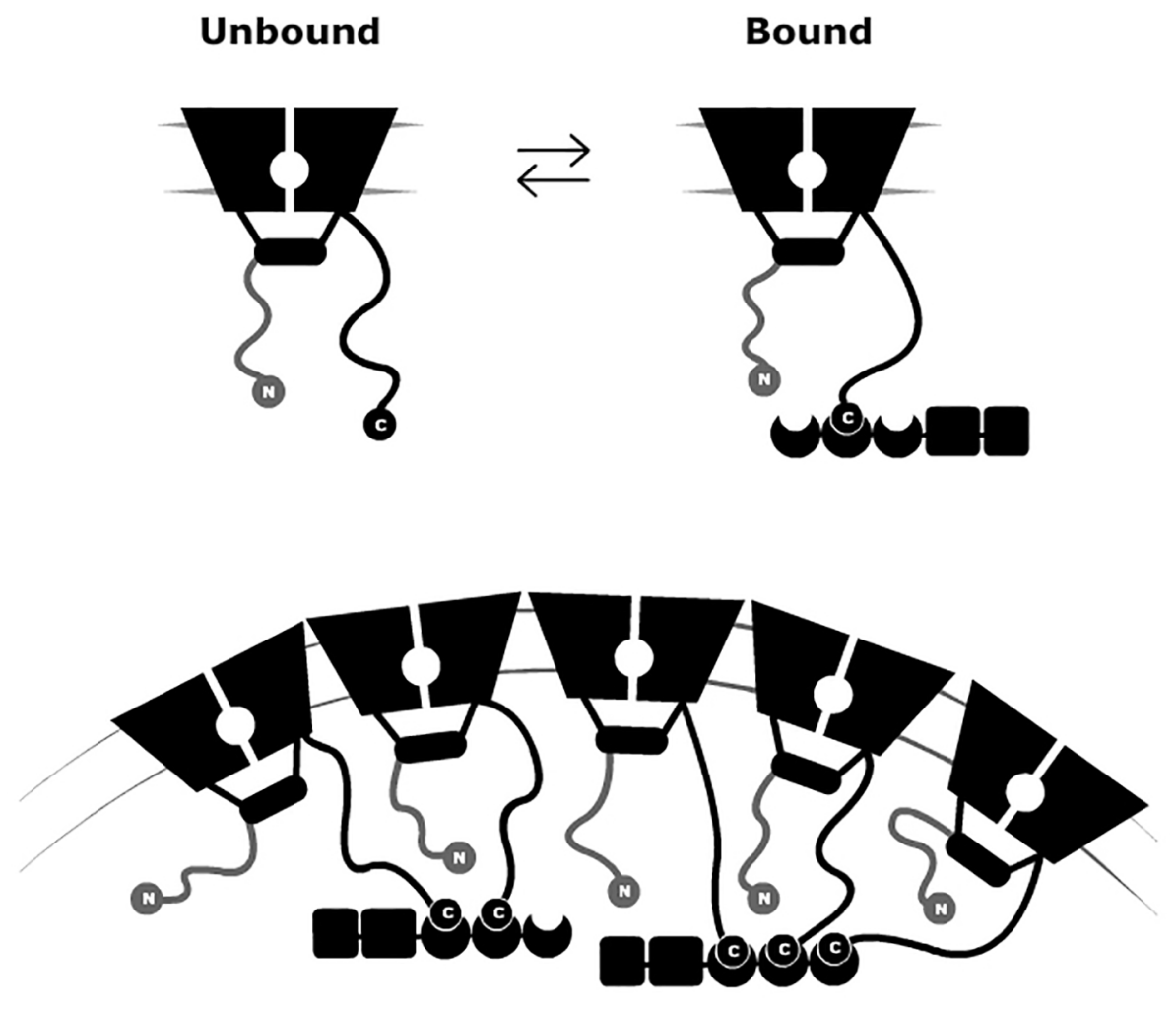

FIGURE 2 | A "ball and chain" mechanism for Kv channel clustering. Schematic representation of the "ball and chain" mechanism for channel binding to PSD-95 (upper panel). In the inter-molecular 'ball and chain' binding mechanism, the interaction of the Kv channel with the membrane-associated PSD-95 scaffold protein is precisely timed, as determined by C-terminal chain length, upon binding of the "chain"-tethered peptide "ball" to the PSD-95 PDZ domain(s). Given the stoichiometry of the interaction and the ability of PSD-95 to aggregate, channel clustering results (lower panel). The membrane-embedded portion corresponds to the channel voltage-sensor and pore domains, while the rectangular shape corresponds to the T1 assembly domain. The crescent, box, and rectangular shapes represent the PDZ, SH3, and guanylate kinase-like domains of the PSD-95 protein, respectively. PSD, post-synaptic density. 
A

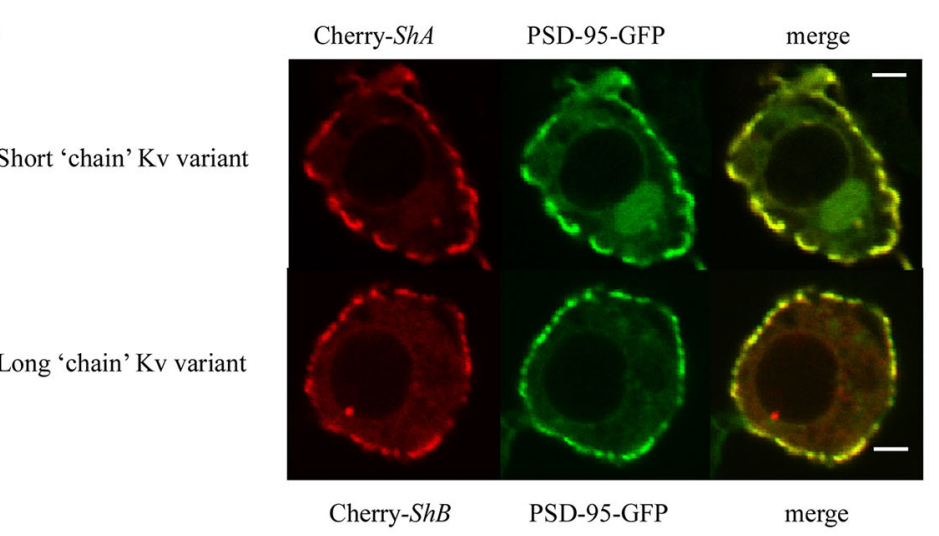

B
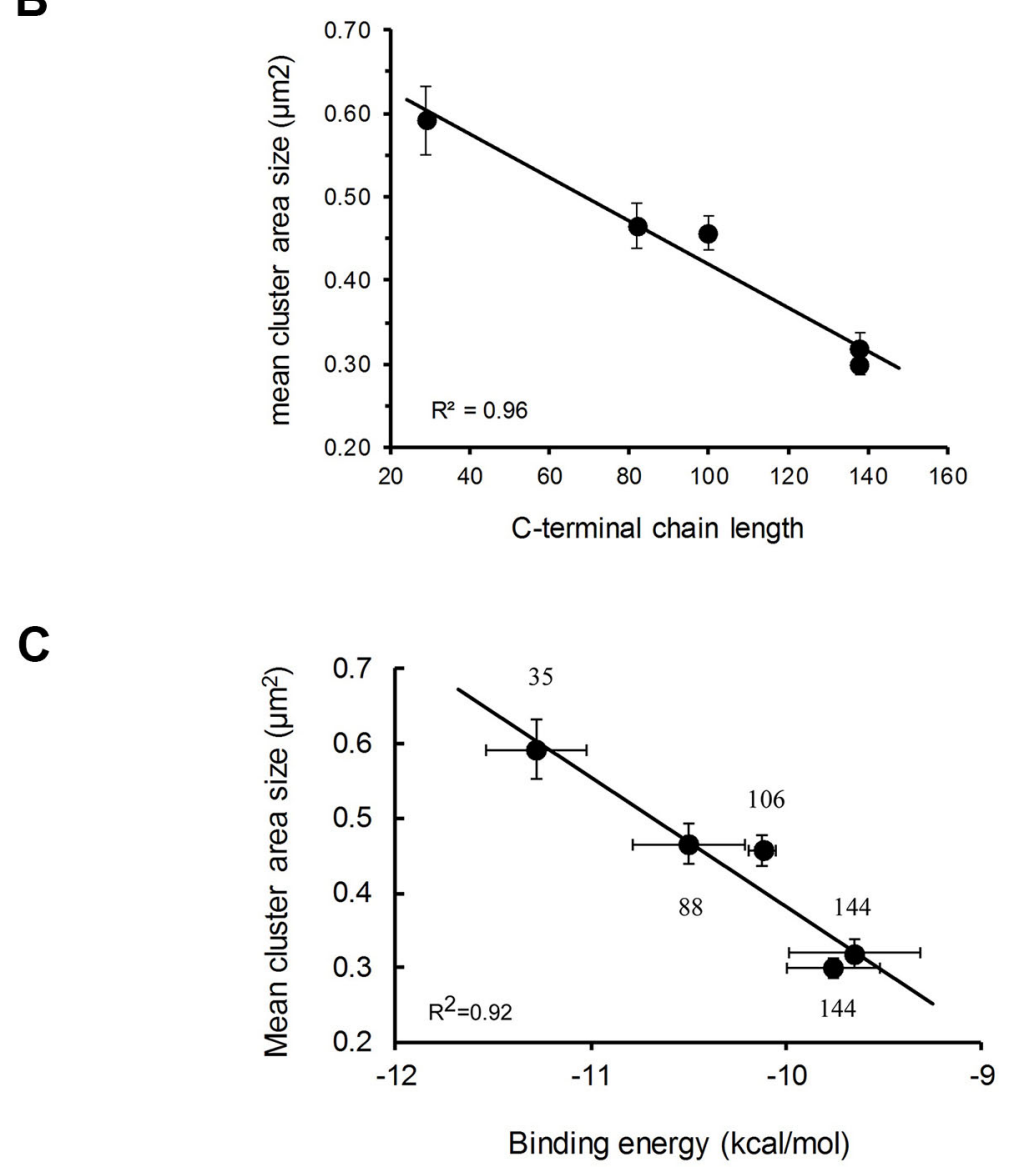

FIGURE 3 | Molecular and cellular correlates in PSD-95-mediated Kv channel clustering. (A) Typical confocal microscopy analysis of Drosophila Schneider S2 cells co-expressing PSD-95-GFP and either the short or long native (alternatively-spliced) Kv channel "chain" length variants. For each cell, three images are shown, with the red channel-associated and green PSD-95-associated fluorescence signals presented in the left and middle columns, respectively. The merged image is shown in the right column. Scale bars correspond to $2 \mu ; \mathrm{m}$. Numbers next to each channel notation indicate C-terminal amino acid "chain" length (adopted with permission from Zandany et al., 2015a). (B) Dependence of the mean mega-cluster area size of different Kv channel "chain" length variants on the C-terminal "chain" length. The solid curve corresponds to linear regression with an $R^{2}$ value of 0.96 . (C) Correlation plot relating the mean cluster area size of the different Kv channel "chain" length variants, as supported by PSD-95, and the binding affinity of the different variants to PSD-95. The solid curve represents linear regression between the compared quantities $\left(R^{2}=0.92\right)$. It is possible that such a linear correlation breaks down for too short "chains" due to steric considerations stemming from the inability of multiple Kv channel molecules to bind PSD-95 when the "chain" is too short. Numbers next to each channel notation indicate C-terminal "chain" length in terms of amino acid numbers. PSD, post-synaptic density. 
Two major criteria support the proposed "ball and chain" mechanism for channel binding to PSD-95 (Zandany et al., 2015a; Zandany et al., 2015b). First, thermodynamic binding analyses showed that the association of the $\mathrm{Kv}$ channel Cterminal "chain" peptide with PSD-95 is entropy -controlled in a manner dictated by "chain" length. Second, the association rate constant of the two proteins depends on "chain" length according to a power-law relation, as predicted by polymer chain theory (Zandany et al., 2015a). Direct support for the analogy between the fast inactivation and channel binding to PSD-95 "ball and chain mechanisms" was recently obtained using a "chain"-level chimeric channel approach, where it was shown that different alternatively spliced and intrinsically-disordered $\mathrm{N}$ - and C-terminal "chain" variants were able to replace one another in the corresponding fast inactivation or PSD-95 binding processes (Lewin et al., 2019). Furthermore, the swapped "chains" affected the relevant fast inactivation or PSD-95 binding processes in a length-dependent manner, as predicted by the random flight "chain" theory underlying the "ball and chain" mechanism (Lewin et al., 2019).

What is the relevance of the molecular "ball and chain" mechanism to cellular Shaker channel clustering (Figure 2, lower panel)? Clearly, one important aspect is the stoichiometry of the interaction involving the three PDZ domains of PSD-95 and the four "chains" of the tetrameric Kv channel (Gomperts, 1996). Furthermore, the ability of PSD-95 protein to self-aggregate may also help rationalize how multiple ion channels and/or PSD-95 molecules realize close proximity (Hsueh et al., 1997; Ghosh et al., 2018). Given the "chain"-length dependence of the Kv channelPSD-95 interaction, combined with stoichiometry considerations, one can ask whether Kv channel "chain" length affects attributes of channel clustering, such as cell surface expression, cluster area size or density. These questions are particularly interesting given that alternative splicing of the Kv channel gene produces Kv channel variants exhibiting distinct "chain" lengths yet which present identical terminal "ball" motifs (Kamb et al., 1988; Schwarz et al., 1988). It has been shown that the level of PSD-95-mediated channel membrane surface expression is dependent on "chain" length, with the shorter "chain" length native Shaker channel splice variant exhibiting higher affinity to PSD-95 and higher levels of expression, as compared to the longer, lower affinity native channel variant (Zandany et al., 2015a). The same variants further exhibited differences in cluster area size, with the short "chain" variant presenting clusters covering larger areas (Figure 3A) (Zandany et al., 2015a). Moreover, confocal imaging analyses of embryonic Drosophila Schneider cells transfected to express PSD-95, together with a series of $\mathrm{Kv}$ channel native and artificial "chain"-length variants, revealed "chain length"-dependence of Kv channel cluster area size (Lewin et al., 2019). Specifically, the shorter the Kv channel C-terminal "chain", the larger was the cluster area size observed (Figure 3B) (Lewin et al., 2019). Furthermore, the cluster area size of any $\mathrm{Kv}$ channel-PSD-95 protein pair was found to linearly correlate with the observed affinity between the two proteins (Figure 3C). These results carry important consequences for understanding the regulation of $\mathrm{Kv}$ channel clustering. Finetuning of channel clustering may not only be achieved by differences in spatial-temporal expression of the PSD-95-related affinity variants (Mottes and Iverson, 1995; Ingleby et al., 2009) but also can result from heterologous subunit assembly (Isacoff et al., 1990; McCormack et al., 1990). Different combinations of long and short C-terminal "chain" variants may thus lead to the appearance of channels with a repertoire of affinities towards PSD-95 and hence, possibly to distinct channel cluster area sizes and densities. Such regulation is expected to have a profound implication on electrical signaling. Taken together, the results summarized in Figure 3 reveal the cellular correlates of the molecular "ball and chain" mechanism concerning channel clustering. Kv channel "chain" length not only affects affinity to the PSD-95 scaffold protein but further determines $\mathrm{Kv}$ channel surface expression and cluster area size. Given the extended intrinsically-disordered nature of this random "chain", this emphasizes the entropy-based regulation mode of Kv channel clustering, which mirrors the thermodynamic entropy signature of the preceding $\mathrm{Kv}$ channel-PSD-95 molecular binding step (Zandany et al., 2015b).

Nevertheless, several questions related to the regulation of Shaker Kv channel clustering await answers. What regulation strategies are employed at the "chain" and "ball" levels to control channel binding to PSD-95, and as such, Kv channel clustering? Does Kv channel "chain" length affect ion channel density? Does the C-terminal "chain" play an active or a passive role in channel clustering? Does crosstalk exist between the inactivation and clustering "ball and chain" mechanisms? Is "chain" length a primary factor that determines the binding specificity of PSD-95 towards its multiple membrane protein partners, or posttranslational modifications are also involved? While these questions remain to be answered, the "ball and chain" description of $\mathrm{Kv}$ channel binding to scaffold proteins provides a simple mechanistic framework for studying $\mathrm{Kv}$ channel clustering. It offers a reference framework to analyze, compare, and interpret data and allows for rationalizing different regulation strategies for channel clustering.

\section{FUTURE CHALLENGES AND DIRECTIONS}

While a known mechanism for the ion channel-scaffold protein interaction is definitely valuable for answering the questions posed above, it is not enough. We still need a reliable quantitative approach to ion channel clustering that can presently only be achieved via high-resolution imaging of channel clustering. In the past, ion channel clustering was usually studied using conventional confocal imaging light microscopy that allows for resolutions up to $250 \mathrm{~nm}$ in the lateral direction. At such low resolution, quantitative assessment of channel clustering yields only limited basic information on surface expression and megacluster area size (Zandany et al, 2015a; Lewin et al., 2019). Recent advances in imaging techniques, in particular, in superresolution imaging methodologies, offer improved spatial resolution reaching $30 \mathrm{~nm}$, a value that may enable the further studying of clustering at the single-molecule level (Sieben et al., 2018; Schermelleh et al., 2019). Such methodologies, particularly single-molecule localization methods (SML), will further enable evaluating important quantitative attributes of channel clustering, 
such as ion channel densities within cluster sites, number of clusters per membrane area and average number of molecules in a cluster, to mention only a few. It may further enable understanding the various regulation strategies that may affect ion channel density. The premise of such an approach was elegantly demonstrated in a recent paper by Shapiro and colleagues studying ion channel clustering using stochastic optical reconstruction SML microscopy (STORM) (Zhang et al., 2016). In this study, the authors demonstrated scaffold protein (the AKAP protein)mediated cluster formation involving direct association of different ion channel types. The analysis reported the distribution of clusters according to area size and the relative proximity of the clusters. Their results provided unexpected and novel insight into the role of coupling among different channel types for electrical signaling. As in all reported cases of ion channel coupling due to channel clustering, the channel determinants responsible for such potentially inter-molecular allosteric coupling remain to be identified (Zhang et al., 2016).

Additional important insight into ion channel clustering can be obtained by employing crystallographic and X-ray scattering analyses. Relying on these methods, combined with thermodynamic analyses, Rodzli and colleagues recently showed that the isolated C-terminal peptide of the Kir 2.1 channel, when fused to the first two PDZ domains of PSD-95, forms a cubic-packed, highly organized oligomeric scaffold (Rodzli et al., 2019). These data suggest that 'chain' binding to PSD-95 provides a switch with which to initiate channel clustering, probably via self-assembly of repeating scaffold units. It would be interesting to examine how changes in length and composition of the peptide "chain" would impact the properties of this compound scaffold.

\section{CONCLUDING REMARKS}

In the current review, using the concrete example of PSD-95mediated Shaker $\mathrm{Kv}$ channel clustering, we emphasized that insight into cellular ion channel clustering can be obtained

\section{REFERENCES}

Arancibia-Carcamo, I. L., and Attwell, D. (2014). The node of Ranvier in CNS pathology. Acta Neuropathol. 128, 161-175. doi: 10.1007/s00401-014-1305-Z

Århem, P., and Blomberg, C. (2007). Ion channel density and threshold dynamics of repetitive firing in a cortical neuron model. BioSystems 89, 117-125. doi: 10.1016/j.biosystems.2006.03.015

Århem, P., Klement, G., and Blomberg, C. (2006). Channel density regulation of firing patterns in a cortical neuron model. Biophys. J. 90, 4392-4404. doi: 10.1529/biophysj.105.077032

Akemann, W., Lundby, A., Mutoh, H., and Knöpfel, T. (2009). Effect of voltage sensitive fluorescent proteins on neuronal excitability. Biophys. J. 96, 39593976. doi: 10.1016/j.bpj.2009.02.046

Armstrong, C. M., and Bezanilla, F. (1977). Inactivation of the sodium channel. II. Gating current experiments. J. Gen. Physiol. 70, 567-590. doi: 10.1085/ jgp.70.5.567

Armstrong, C. M. (1981). Sodium channels and gating currents. Physiol. Rev. 61, 644-683. doi: 10.1152/physrev.1981.61.3.644

Boeckers, T. M. (2006). The postsynaptic density. Cell Tiss. Res. 326, 409-422. doi: 10.1007/s00441-006-0274-5 when the molecular mechanism controlling ion channelscaffold protein interaction is known. Identifying the interacting scaffold protein partners responsible for active ion channel clustering is only the first step towards understanding the clustering process. Knowing the molecular mechanism underlying this interaction, combined with super-resolution confocal microscopy, in particular, single-molecule localization microscopy that allows direct observation of channel clustering at the molecular level, may serve to bridge the molecular and cellular gap in understanding channel clustering. This strategy may further provide a framework to analyze pressing questions regarding the specific clustering of the ion channel under study, in particular, those related to the manner(s) by which the ion channel clustering process is regulated to affect ion channel density. Given the seminal importance of ion channel density in affecting action potential conduction properties, brought about by changes in ionic current densities, ion channel gating properties and/or membrane capacitance, efforts to reveal such mechanisms are paramount and are expected to shed more light on the hidden dimension of ion channel density regulation.

\section{AUTHOR CONTRIBUTIONS}

$\mathrm{VN}$ and $\mathrm{OY}$ wrote the manuscript.

\section{ACKNOWLEDGMENTS}

This research was supported by the Israel Science Foundation (grant 294/16 to OY).

\section{SUPPLEMENTARY MATERIAL}

The Supplementary Material for this article can be found online at: https://www.frontiersin.org/articles/10.3389/fphar.2019. 01644/full\#supplementary-material

Bruneau, E. G., Brenner, D. S., Kuwada, J. Y., and Akaaboune, M. (2008). Acetylcholine receptor clustering is required for the accumulation and maintenance of scaffolding proteins. Curr. Biol. 18, 109-115. doi: 10.1016/ j.cub.2007.12.029

Burden, S. J., Huijbers, M. G., and Remedio, L. (2018). Fundamental molecules and mechanisms for forming and maintaining neuromuscular synapses. Int. J. Mol. Sci. 19, 490. doi: 10.3390/ijms 19020490

Capera, J., Serrano-Novillo, C., Navarro-Pérez, M., Cassinelli, S., and Felipe, A. (2019). The potassium channel odyssey: mechanisms of traffic and membrane arrangement. Int. J. Mol. Sci. 20, 734. doi: 10.3390/ijms20030734

Chang, K.-J., and Rasband, M. N. (2013). Excitable domains of myelinated nerves: axon initial segments and nodes of Ranvier. Curr. Top. Membr. 5, 159-192. doi: 10.1016/B978-0-12-417027-8.00005-2

Chen, X., Levy, J. M., Hou, A., Winters, C., Azzam, R., Sousa, A. A., et al. (2015). PSD-95 family MAGUKs are essential for anchoring AMPA and NMDA receptor complexes at the postsynaptic density. Proc. Natl. Acad. Sci. U. S. A. 112, 6983-6992. doi: 10.1073/pnas.1517045112

Cohen, N. A., Brenman, J. E., Snyder, S. H., and Bredt, D. S. (1996). Binding of the inward rectifier K+ channel Kir 2.3 to PSD-95 is regulated by protein kinase A phosphorylation. Neuron 17, 759-767. doi: 10.1016/S0896-6273(00)80207-X 
Debanne, D., Guérineau, N. C., Gähwiler, B. H., and Thompson, S. M. (1997). Action-potential propagation gated by an axonal I(A)-like $\mathrm{K}+$ conductance in hippocampus. Nature 389, 286-289. doi: 10.1038/38502

Devaux, J., Gola, M., Jacquet, G., and Crest, M. (2002). Effects of $\mathrm{K}^{+}$channel blockers on developing rat myelinated CNS axons: identification of four types of $\mathrm{K}^{+}$channels. J. Neurophysiol. 87, 1376-1385. doi: 10.1152/jn.00646.2001

Devaux, J., Alcaraz, G., Grinspan, J., Bennett, V., Joho, R., Crest, M., et al. (2003). Kv3.1b is a novel component of CNS nodes. J. Neurosci. 23, 4509-4518. doi: 10.1523/JNEUROSCI.23-11-04509.2003

Devaux, J. J., Kleopa, K. A., Cooper, E. C., and Scherer, S. S. (2004). KCNQ2 is a nodal K ${ }^{+}$channel. J. Neurosci. 24, 1236-1244. doi: 10.1523/JNEUROSCI.451203.2004

Dixon, R. E., Moreno, C. M., Yuan, C., Opitz-Araya, X., Binder, M. D., Navedo, M. F., et al. (2015). Graded Ca2+/calmodulin-dependent coupling of voltage-gated CaV1.2 channels. eLife 4, e05608. doi: 10.7554/eLife.05608

Dunker, A. K., Lawson, J. D., Brown, C. J., Williams, R. M., Romero, P., Oh, J. S., et al. (2001). Intrinsically disordered protein. J. Mol. Graph. Model. 19, 26-59. doi: 10.1016/S1093-3263(00)00138-8

Dunker, A. K., Brown, C. J., Lawson, J. D., Iakoucheva, L. M., and Obradović, Z. (2002). Intrinsic disorder and protein function. Biochemistry 41, 6573-6582. doi: 10.1021/bi012159+

Engelman, D. M. (2005). Membranes are more mosaic than fluid. Nature 438, 578-580. doi: 10.1038/nature04394

Folci, A., Steinberger, A., Lee, B., Stanika, R., Scheruebel, S., Campiglio, M., et al. (2018). Molecular mimicking of C-terminal phosphorylation tunes the surface dynamics of CaV1.2 calcium channels in hippocampal neurons. J. Biol. Chem. 293, 1040-1053. doi: 10.1074/jbc.M117.799585

Fox, P. D., Loftus, R. J., and Tamkun, M. M. (2013). Regulation of Kv2.1 K ${ }^{+}$ conductance by cell surface channel density. J. Neurosci. 33, 1259-1270. doi: 10.1523/JNEUROSCI.3008-12.2013

Frank, R. A., and Grant, S. G. (2017). Supramolecular organization of NMDA receptors and the postsynaptic density. Curr. Opin. Neurobiol. 45, 139-147. doi: 10.1016/j.conb.2017.05.019

Freeman, S. A., Desmazières, A., Fricker, D., Lubetzki, C., and Sol-Foulon, N. (2016). Mechanisms of sodium channel clustering and its influence on axonal impulse conduction. Cell. Mol. Life Sci. 73, 723-735. doi: 10.1007/s00018-0152081-1

Furutani, K., and Kurachi, Y. (2012). "Heterologous expression systems and analyses of ion channels," in Patch Clamp Techniques (Tokyo): Springer Protocols Handbooks (Springer), 353-370. doi: 10.1007/978-4-431-53993-3_23

Ghosh, A., Ramagopal, U. A., Bonanno, J. B., Brenowitz, M., and Almo, S. C. (2018). Structures of the L27 domain of Disc large homologue 1 protein illustrate a self-assembly module. Biochemistry 57, 1293-1305. doi: 10.1021/ acs.biochem.7b01074

Giese, K. P., Storm, J. F., Reuter, D., Fedorov, N. B., Shao, L. R., Leicher, T., et al. (1998). Reduced $\mathrm{K}^{+}$channel inactivation, spike broadening, and after hyperpolarization in Kvbeta1.1-deficient mice with impaired learning. Learn. Mem. 5, 257-273. doi: 10.1101/lm.5.4.257

Gomperts, S. N. (1996). Clustering membrane proteins: it's all coming together with the PSD-95/SAP90 protein family. Cell 84, 659-662. doi: 10.1016/S00928674(00)81043-0

Good, M. C., Zalatan, J. G., and Lim, W. A. (2011). Scaffold Proteins: Hubs for controlling the flow of cellular information. Science 332, 680-686. doi: 10.1126/ science. 1198701

Gundelfinger, E. D., and Fejtova, A. (2012). Molecular organization and plasticity of the cytomatrix at the active zone. Curr. Opin. Neurobiol. 22, 423-430. doi: 10.1016/j.conb.2011.10.005

Han, K., and Kim, E. (2008). Synaptic adhesion molecules and PSD-95. Prog. Neurobiol. 84, 263-283. doi: 10.1016/j.pneurobio.2007.10.011

Hille, B. (1992). Ionic channels of excitable membranes (second edition). FEBS Lett. 306, 277-278. doi: 10.1016/0014-5793(92)81020-M

Hodgkin, A. L., and Huxley, A. F. (1952). A quantitative description of membrane current and its application to conduction and excitation in nerve. J. Physiol. (Lond.) 117, 500-544. doi: 10.1113/jphysiol.1952.sp004764

Hodgkin, A. L. (1948). The local electric changes associated with repetitive action in a non-medullated axon. J. Physiol. 107, 165-181. doi: 10.1113/ jphysiol.1948.sp004260
Hoffmann, B., Klöcker, N., Benndorf, K., and Biskup, C. (2015). Visualization of the dynamics of PSD-95 and Kir2.1 interaction by fluorescence lifetime-based resonance energy transfer imaging. Medical Photonics 27, 70-82. doi: 10.1016/ j.medpho.2014.11.001

Hoshi, T., Zagotta, W. N., and Aldrich, R. W. (1990). Biophysical and molecular mechanisms of Shaker potassium channel inactivation. Science 250, 533-538. doi: 10.1126/science. 2122519

Hossain, M. I., Iwasaki, H., Okochi, Y., Chahine, M., Higashijima, S., Nagayama, K., et al. (2008). Enzyme domain affects the movement of the voltage sensor in ascidian and zebrafish voltage-sensing phosphatases. J. Biol. Chem. 283, 18248-18259. doi: 10.1074/jbc.M706184200

Hsueh, Y. P., Kim, E., and Sheng, M. (1997). Disulfide-linked head-to-head multimerization in the mechanism of ion channel clustering by PSD-95. Neuron 18, 803-814. doi: 10.1016/S0896-6273(00)80319-0

Huxley, A. F. (1964). Excitation and conduction in nerve: quantitative analysis. Science 145, 1154-1159. doi: 10.1126/science.145.3637.1154

Ingleby, L., Maloney, R., Jepson, J., Horn, R., and Reenan, R. (2009). Regulated RNA editing and functional epistasis in Shaker potassium channels. J. Gen. Physiol. 133, 17-27. doi: 10.1085/jgp.200810133

Isacoff, E. Y., Jan, Y. N., and Jan, L. Y. (1990). Evidence for the formation of heteromultimeric potassium channels in Xenopus oocytes. Nature 345, 530534. doi: 10.1038/345530a0

Jensen, C. S., Watanabe, S., Stas, J. I., Klaphaak, J., Yamane, A., Schmitt, N., et al. (2017). Trafficking of Kv2.1 channels to the axon initial segment by a novel nonconventional secretory pathway. J. Neurosci. 37, 11523-11536. doi: 10.1523/JNEUROSCI.3510-16.2017

Johnston, D., Hoffman, D. A., Colbert, C. M., and Magee, J. C. (1999). Regulation of back-propagating action potentials in hippocampal neurons. Curr. Opin. Neurobiol. 9, 288-292. doi: 10.1016/s0959-4388(99)80042-7

Joseph, B. K., Thakali, K. M., Pathan, A. R., Kang, E., Rusch, N. J., and Rhee, S. W. (2011). Postsynaptic density-95 scaffolding of Shaker-type $\mathrm{K}^{+}$channels in smooth muscle cells regulates the diameter of cerebral arteries. J. Physiol. (Lond.) 589, 5143-5152. doi: 10.1113/jphysiol.2011.213843

Kaeser, P. S., Deng, L., Wang, Y., Dulubova, I., Liu, X., Rizo, J., et al. (2011). RIM proteins tether $\mathrm{Ca}^{2+}$-channels to presynaptic active zones via a direct PDZdomain interaction. Cell 144, 282-295. doi: 10.1016/j.cell.2010.12.029

Kamb, A., Tseng-Crank, J., and Tanouye, M. A. (1988). Multiple products of the Drosophila Shaker gene may contribute to potassium channel diversity. Neuron 1, 421-430. doi: 10.1016/0896-6273(88)90192-4

Kim, E., Niethammer, M., Rothschild, A., Jan, Y. N., and Sheng, M. (1995). Clustering of Shaker-type $\mathrm{K}^{+}$channels by interaction with a family of membrane-associated guanylate kinases. Nature 378, 85-88. doi: 10.1038/ $378085 \mathrm{a} 0$

Klinger, F., Gould, G., Boehm, S., and Shapiro, M. S. (2011). Distribution of Mchannel subunits KCNQ2 and KCNQ3 in rat hippocampus. Neuroimage. 58, 761-769. doi: 10.1016/j.neuroimage.2011.07.003

Kole, M. H. P., Letzkus, J. J., and Stuart, G. J. (2007). Axon initial segment Kv1 channels control axonal action potential waveform and synaptic efficacy. Neuron 55, 633-647. doi: 10.1016/j.neuron.2007.07.031

Kole, M. H. P., Ilschner, S. U., Kampa, B. M., Williams, S. R., Ruben, P. C., and Stuart, G. J. (2008). Action potential generation requires a high sodium channel density in the axon initial segment. Nat. Neurosci. 11, 178-186. doi: 10.1038/ nn2040

Komada, M., and Soriano, P. (2002). BIV-spectrin regulates sodium channel clustering through ankyrin-G ax axon initial segments and nodes of Ranvier. J. Cell Biol. 156, 337-348. doi: 10.1083/jcb.200110003

Krinner, S., Butola, T., Jung, S., Wichmann, C., and Moser, T. (2017). RIMbinding protein 2 promotes a large number of $\mathrm{CaV} 1.3 \mathrm{Ca}^{2+}$-channels and contributes to fast synaptic vesicle replenishment at hair cell active zones. Front. Cell Neurosci. 11, 334. doi: 10.3389/fncel.2017.00334

Lai, H. C., and Jan, L. Y. (2006). The distribution and targeting of neuronal voltage-gated ion channels. Nat. Rev. Neurosci. 7, 548-562. doi: 10.1038/ nrn 1938

Lee, H.-J., and Zheng, J. J. (2010). PDZ domains and their binding partners: structure, specificity, and modification. CCS, 8, 8. doi: 10.1186/1478-811X-8-8

Lee, S., Lee, K., Hwang, S., Kim, S. H., Song, W. K., Park, Z. Y., et al. (2006). SPIN90/WISH interacts with PSD-95 and regulates dendritic spinogenesis via 
an N-WASP-independent mechanism. EMBO J. 25, 4983-4995. doi: 10.1038/ sj.emboj.7601349

Lee, A., Fakler, B., Kaczmarek, L. K., and Isom, L. L. (2014). More than a pore: ion channel signaling complexes. J. Neurosci. 34, 15159-15169. doi: 10.1523/ JNEUROSCI.3275-14.2014

Lemaillet, G., Walker, B., and Lambert, S. (2003). Identification of a conserved Ankyrin-binding motif in the family of sodium channel $\alpha$ subunits. J. Biol. Chem. 278, 27333-27339. doi: 10.1074/jbc.M303327200

Lewin, L., Nirenberg, V., Yehezkel, R., Naim, S., Abdu, U., Orr, I., et al. (2019). Direct evidence for a similar molecular mechanism underlying $\mathrm{Kv}$ channel fast inactivation and clustering. J. Mol. Biol. 431, 542-556. doi: 10.1016/ j.jmb.2018.12.002

Li, D., Takimoto, K., and Levitan, E. S. (2000). Surface expression of Kv1 channels is governed by a C-terminal motif. J. Biol. Chem. 275, 11597-11602. doi: 10.1074/jbc.275.16.11597

Liu, R., Yang, G., Zhou, M.-H., He, Y., Mei, Y.-A., and Ding, Y. (2016). Flotillin-1 downregulates $\mathrm{K}^{+}$current by directly coupling with Kv2.1 subunit. Protein Cell 7, 455-460. doi: 10.1007/s13238-016-0276-3

Lundby, A., Mutoh, H., Dimitrov, D., Akemann, W., and Knöpfel, T. (2008). Engineering of a genetically encodable fluorescent voltage sensor exploiting fast Ci-VSP voltage-sensing movements. PloS One 3, e2514. doi: 10.1371/ journal.pone.0002514

Magidovich, E., Orr, I., Fass, D., Abdu, U., and Yifrach, O. (2007). Intrinsic disorder in the $\mathrm{C}$-terminal domain of the Shaker voltage-activated $\mathrm{K}+$ channel modulates its interaction with scaffold proteins. Proc. Natl. Acad. Sci. U. S. A. 104, 13022-13027. doi: 10.1073/pnas.0704059104

McCormack, K., Lin, J. W., Iverson, L. E., and Rudy, B. (1990). Shaker K ${ }^{+}$channel subunits from heteromultimeric channels with novel functional properties. Biochem. Biophys. Res. Commun. 171, 1361-1371. doi: 10.1016/0006-291x(90) 90836-c

Miki, T., Kaufmann, W. A., Malagon, G., Gomez, L., Tabuchi, K., Watanabe, M., et al. (2017). Numbers of presynaptic $\mathrm{Ca}^{2+}$ channel clusters match those of functionally defined vesicular docking sites in single central synapses. Proc. Natl. Acad. Sci. U. S. A. 114, 5246-5255. doi: 10.1073/pnas.1704470114

Molina, M. L., Barrera, F. N., Fernández, A. M., Poveda, J. A., Renart, M. L., Encinar, J. A., et al. (2006). Clustering and coupled gating modulate the activity in KcsA, a potassium channel model. J. Biol. Chem. 281, 18837-18848. doi: 10.1074/jbc.M600342200

Mottes, J. R., and Iverson, L. E. (1995). Tissue-specific alternative splicing of hybrid Shaker/lacZ genes correlates with kinetic differences in Shaker K+ currents in vivo. Neuron 14, 613-623. doi: 10.1016/0896-6273(95)90318-6

O'Connell, K. M. S., Loftus, R., and Tamkun, M. M. (2010). Localizationdependent activity of the Kv2.1 delayed-rectifier $\mathrm{K}^{+}$channel. Proc. Natl. Acad. Sci. U. S. A. 107, 12351-12356. doi: 10.1073/pnas.1003028107

Ogawa, Y., Horresh, I., Trimmer, J. S., Bredt, D. S., Peles, E., and Rasband, M. N. (2008). Postsynaptic density-93 clusters Kv1 channels at axon initial segments independently of Caspr2. J. Neurosci. 28, 5731-5739. doi: 10.1523/ JNEUROSCI.4431-07.2008

Patrizio, A., Renner, M., Pizzarelli, R., Triller, A., and Specht, C. G. (2017). Alpha subunit-dependent glycine receptor clustering and regulation of synaptic receptor numbers. Sci. Rep. 7, 1-11. doi: 10.1038/s41598-017-11264-3

Peng, H. B., and Poo, M. (1986). Formation and dispersal of acetylcholine receptor clusters in muscle cells. Trends Neurosci. 9, 125-129. doi: 10.1016/0166-2236 (86)90041-X

Poliak, S., Salomon, D., Elhanany, H., Sabanay, H., Kiernan, B., Pevny, L., et al. (2003). Juxtaparanodal clustering of Shaker-like $\mathrm{K}^{+}$channels in myelinated axons depends on Caspr2 and TAG-1. J. Cell Biol. 162, 1149-1160. doi: $10.1083 /$ jcb. 200305018

Prescott, S. A., De Koninck, Y., and Sejnowski, T. J. (2008). Biophysical basis for three distinct dynamical mechanisms of action potential initiation. PloS Comput. Biol. 4, e1000198. doi: 10.1371/journal.pcbi.1000198

Rasband, M. N., and Trimmer, J. S. (2001). Developmental clustering of ion channels at and near the node of ranvier. Dev. Biol. 236, 5-16. doi: 10.1006/ dbio.2001.0326

Rasband, M. N., Park, E. W., Zhen, D., Arbuckle, M. I., Poliak, S., Peles, E., et al (2002). Clustering of neuronal potassium channels is independent of their interaction with PSD-95. J. Cell Biol. 159, 663-672. doi: 10.1083/ jcb.200206024
Rasband, M. N. (2004). It's “juxta” potassium channel! J. Neurosci. Res. 76, 749757. doi: $10.1002 /$ jnr.20073

Rasband, M. N. (2010). Clustered K+ channel complexes in axons. Neurosci. Lett. 486, 101-106. doi: 10.1016/j.neulet.2010.08.081

Rinzel, J., and Ermentrout, B. (1998). "Analysis of neural excitability and oscillations," in Methods in Neuronal Modeling: From Ions to Networks. Eds. C. Koch and I. Segev (Cambridge MA: The MIT Press), 251-291.

Rodzli, N., Lockhart-Cairns, M., Levy, C., Chipperfield, J., Bird, L., Baldock, C., et al. (2019). How the dual PDZ domain from Postsynaptic density protein 95 clusters ion channels and receptors. bioRxiv, 775726. doi: 10.1101/775726

Südhof, T. C. (2012). The presynaptic active zone. Neuron 75, 11-25. doi: 10.1016/ j.neuron.2012.06.012

Sakmann, B., and Neher, E. (1984). Patch clamp techniques for studying ionic channels in excitable membranes. Annu. Rev. Physiol. 46, 455-472. doi: 10.1146/annurev.ph.46.030184.002323

Sarmiere, P. D., Weigle, C. M., and Tamkun, M. M. (2008). The Kv2.1 K+ channel targets to the axon initial segment of hippocampal and cortical neurons in culture and in situ. BMC Neurosci. 9, 112. doi: 10.1186/1471-2202-9-112

Scannevin, R. H., Murakoshi, H., Rhodes, K. J., and Trimmer, J. S. (1996). Identification of a cytoplasmic domain important in the polarized expression and clustering of the Kv2.1 K ${ }^{+}$channel. J. Cell Biol. 135, 1619-1632. doi: 10.1083/jcb.135.6.1619

Schaefer, N., Roemer, V., Janzen, D., and Villmann, C. (2018). Impaired glycine receptor trafficking in neurological diseases. Front. Mol. Neurosci. 11, 291. doi: 10.3389/fnmol.2018.00291

Scheefhals, N., and MacGillavry, H. D. (2018). Functional organization of postsynaptic glutamate receptors. Mol. Cell. Neurosci. 91, 82-94. doi: 10.1016/j.mcn.2018.05.002

Schermelleh, L., Ferrand, A., Huser, T., Eggeling, C., Sauer, M., Biehlmaier, O., et al. (2019). Super-resolution microscopy demystified. Nat. Cell Biol. 21, 7284. doi: 10.1038/s41556-018-0251-8

Schwarz, T. L., Tempel, B. L., Papazian, D. M., Jan, Y. N., and Jan, L. Y. (1988). Multiple potassium-channel components are produced by alternative splicing at the Shaker locus in Drosophila. Nature 331, 137-142. doi: 10.1038/331137a0

Sieben, C., Douglass, K. M., Guichard, P., and Manley, S. (2018). Super-resolution microscopy to decipher multi-molecular assemblies. Curr. Opin. Struct. Biol. 49, 169-176. doi: 10.1016/j.sbi.2018.03.017

Singer, S. J., and Nicolson, G. L. (1972). The fluid mosaic model of the structure of cell membranes. Science 175, 720-731. doi: 10.1126/science.175.4023.720

Slater, C. R. (2017). The structure of human neuromuscular junctions: some unanswered molecular questions. Int. J. Mol. Sci. 18, 2183. doi: 10.3390/ ijms18102183

St-Hilaire, M., and Longtin, A. (2004). Comparison of coding capabilities of Type I and Type II neurons. J. Comput. Neurosci. 16, 299-313. doi: 10.1023/B: JCNS.0000025690.02886.93

Sumino, A., Yamamoto, D., Iwamoto, M., Dewa, T., and Oiki, S. (2014). Gatingassociated clustering-dispersion dynamics of the KcsA potassium channel in a lipid membrane. J. Phys. Chem. Lett. 5, 578-584. doi: 10.1021/jz402491t

Tang, A.-H., Chen, H., Li, T. P., Metzbower, S. R., MacGillavry, H. D., and Blanpied, T. A. (2016). A trans-synaptic nanocolumn aligns neurotransmitter release to receptors. Nature 536, 210-214. doi: 10.1038/nature19058

Tateno, T., and Robinson, H. P. C. (2006). Rate coding and spike-time variability in cortical neurons with two types of threshold dynamics. J. Neurophysiol. 95, 2650-2663. doi: 10.1152/jn.00683.2005

Tateno, T., and Robinson, H. P. C. (2007). Phase resetting curves and oscillatory stability in interneurons of rat somatosensory cortex. Biophys. J. 92, 683-695. doi: 10.1529/biophysj.106.088021

Tateno, T., Harsch, A., and Robinson, H. P. C. (2004). Threshold firing frequencycurrent relationships of neurons in rat somatosensory cortex: type 1 and type 2 dynamics. J. Neurophysiol. 92, 2283-2294. doi: 10.1152/jn.00109.2004

Tejedor, F. J., Bokhari, A., Rogero, O., Gorczyca, M., Zhang, J., Kim, E., et al. (1997). Essential role for dlg in synaptic clustering of Shaker $\mathrm{K}^{+}$channels in vivo. J. Neurosci. 17, 152-159. doi: 10.1523/JNEUROSCI.17-01-00152.1997

Tian, C., Wang, K., Ke, W., Guo, H., and Shu, Y. (2014). Molecular identity of axonal sodium channels in human cortical pyramidal cells. Front. Cell Neurosci. 8, 297. doi: 10.3389/fncel.2014.00297

Tiffany, A. M., Manganas, L. N., Kim, E., Hsueh, Y. P., Sheng, M., and Trimmer, J. S. (2000). PSD-95 and SAP97 exhibit distinct mechanisms for regulating $\mathrm{K}^{+}$channel 
surface expression and clustering. J. Cell Biol. 148, 147-157. doi: 10.1083/ jcb.148.1.147

Trimmer, J. S. (1991). Immunological identification and characterization of a delayed rectifier $\mathrm{K}^{+}$channel polypeptide in rat brain. Proc. Natl. Acad. Sci. U. S. A. $88,10764-10768$. doi: $10.1073 /$ pnas. 88.23 .10764

Trimmer, J. S. (2015). Subcellular localization of $\mathrm{K}^{+}$channels in mammalian brain neurons: remarkable precision in the midst of extraordinary complexity. Neuron 85, 238-256. doi: 10.1016/j.neuron.2014.12.042

Uversky, V. N., and Dunker, A. K. (2010). Understanding protein non-folding. Biochim. Biophys. Acta 1804, 1231-1264. doi: 10.1016/j.bbapap. 2010.01.017

Verpelli, C., Schmeisser, M. J., Sala, C., and Boeckers, T. M. (2012). Scaffold proteins at the postsynaptic density. Adv. Exp. Med. Biol. 970, 29-61. doi: 10.1007/978-3-7091-0932-8_2

Vivas, O., Moreno, C. M., Santana, L. F., and Hille, B. (2017). Proximal clustering between $\mathrm{BK}$ and $\mathrm{CaV} 1.3$ channels promotes functional coupling and BK channel activation at low voltage. Elife 6. doi: 10.7554/eLife.28029

Zandany, N., Lewin, L., Nirenberg, V., Orr, I., and Yifrach, O. (2015a). Entropic clocks in the service of electrical signaling: "Ball and chain"mechanisms for ion channel inactivation and clustering. FEBS Lett. 589, 2441-2447. doi: 10.1016/ j.febslet.2015.06.010

Zandany, N., Marciano, S., Magidovich, E., Frimerman, T., Yehezkel, R., Shem-Ad, T., et al. (2015b). Alternative splicing modulates $\mathrm{Kv}$ channel clustering through a molecular ball and chain mechanism. Nat. Commun. 6, 6488. doi: 10.1038/ ncomms 7488

Zeberg, H., Blomberg, C., and Arhem, P. (2010). Ion channel density regulates switches between regular and fast spiking in soma but not in axons. PloS Comput. Biol. 6, e1000753. doi: 10.1371/journal.pcbi.1000753
Zeberg, H., Robinson, H. P. C., and Århem, P. (2015). Density of voltage-gated potassium channels is a bifurcation parameter in pyramidal neurons. J. Neurophysiol. 113, 537-549. doi: 10.1152/jn.00907.2013

Zhang, J., Carver, C. M., Choveau, F. S., and Shapiro, M. S. (2016). Clustering and functional coupling of diverse ion channels and signaling poteins revealed by super-resolution STORM microscopy in neurons. Neuron 92, 461-478. doi: 10.1016/j.neuron.2016.09.014

Zheng, C.-Y., Seabold, G. K., Horak, M., and Petralia, R. S. (2011). MAGUKs, Synaptic development, and synaptic plasticity. Neuroscientist 17, 493-512. doi: $10.1177 / 1073858410386384$

Zhou, D., Lambert, S., Malen, P. L., Carpenter, S., Boland, L. M., and Bennett, V. (1998). AnkyrinG is required for clustering of voltage-gated $\mathrm{Na}$ channels at axon initial segments and for normal action potential firing. J. Cell Biol. 143, 1295-1304. doi: 10.1083/jcb.143.5.1295

Zimmermann, D., Zhou, A., Kiesel, M., Feldbauer, K., Terpitz, U., Haase, W., et al. (2008). Effects on capacitance by overexpression of membrane proteins. Biochem. Bioph. Res. Commun. 369, 1022-1026. doi: 10.1016/j.bbrc.2008.02.153

Conflict of Interest: The authors declare that the research was conducted in the absence of any commercial or financial relationships that could be construed as a potential conflict of interest.

Copyright $\odot 2020$ Nirenberg and Yifrach. This is an open-access article distributed under the terms of the Creative Commons Attribution License (CC BY). The use, distribution or reproduction in other forums is permitted, provided the original author (s) and the copyright owner(s) are credited and that the original publication in this journal is cited, in accordance with accepted academic practice. No use, distribution or reproduction is permitted which does not comply with these terms. 